\title{
Cobaviruses - a new globally distributed phage group infecting Rhodobacteraceae in marine ecosystems
}

\author{
Vera Bischoff ${ }^{1}$ - Boyke Bunk ${ }^{2}$ - Jan P. Meier-Kolthoff $\mathbb{C}^{2}$ - Cathrin Spröer ${ }^{2}$ - Anja Poehlein $\mathbb{C}^{3} \cdot$ Marco Dogs $^{1}$. \\ Mary Nguyen ${ }^{4} \cdot$ Jörn Petersen $\mathbb{D}^{2} \cdot$ Rolf Daniel $\mathbb{D}^{3} \cdot$ Jörg Overmann ${ }^{2} \cdot$ Markus Göker $\mathbb{D}^{2} \cdot$ Meinhard Simon $\mathbb{D}^{1}$. \\ Thorsten Brinkhoff ${ }^{1} \cdot$ Cristina Moraru (i) ${ }^{1}$
}

Received: 7 July 2018 / Revised: 15 January 2019 / Accepted: 22 January 2019 / Published online: 4 February 2019

(c) The Author(s) 2019. This article is published with open access

\begin{abstract}
Bacteriophages are widely considered to influence bacterial communities, however most phages are still unknown or not studied well enough to understand their ecological roles. We have isolated two phages infecting Lentibacter sp. SH36, affiliated with the marine Roseobacter group, and retrieved similar phage genomes from publicly available metagenomics databases. Phylogenetic analysis placed the new phages within the Cobavirus group, in the here newly proposed genus Siovirus and subfamily Riovirinae of the Podoviridae. Gene composition and presence of direct terminal repeats in cultivated cobaviruses point toward a genome replication and packaging strategy similar to the T7 phage. Investigation of the genomes suggests that viral lysis of the cell proceeds via the canonical holin-endolysin pathway. Cobaviral hosts include members of the genera Lentibacter, Sulfitobacter and Celeribacter of the Roseobacter group within the family Rhodobacteraceae (Alphaproteobacteria). Screening more than 5,000 marine metagenomes, we found cobaviruses worldwide from temperate to tropical waters, in the euphotic zone, mainly in bays and estuaries, but also in the open ocean. The presence of cobaviruses in protist metagenomes as well as the phylogenetic neighborhood of cobaviruses in glutaredoxin and ribonucleotide reductase trees suggest that cobaviruses could infect bacteria associated with phototrophic or grazing protists. With this study, we expand the understanding of the phylogeny, classification, genomic organization, biogeography and ecology of this phage group infecting marine Rhodobacteraceae.
\end{abstract}

Supplementary information The online version of this article (https:// doi.org/10.1038/s41396-019-0362-7) contains supplementary material, which is available to authorized users.

Cristina Moraru

liliana.cristina.moraru@uni-oldenburg.de

1 Institute for Chemistry and Biology of the Marine Environment, University of Oldenburg, Carl-von-Ossietzky-Str. 9 -11, D-26111 Oldenburg, Germany

2 Leibniz-Institut DSMZ-Deutsche Sammlung von Mikroorganismen und Zellkulturen GmbH, Inhoffenstraße 7 B, D38124 Braunschweig, Germany

3 Georg-August-University Göttingen, Institute of Microbiology and Genetics, Department of Genomic and Applied Microbiology \& Göttingen Genomics Laboratory, Grisebachstr. 8, D-37077 Göttingen, Germany

4 Centre for Marine Bio-Innovation, School of Biological, Earth and Environmental Sciences, The University of New South Wales, Kensington, NSW 2052, Australia

\section{Introduction}

Viruses infecting bacteria and archaea are abundant in marine systems and are major drivers of biogeochemical cycles, through their ability to lyse cells, express auxiliary metabolic genes (AMG) and mediate horizontal gene transfer [1-3]. Marine habitats contain abundant and extremely diverse viral communities, the majority of which remains uncultivated [4-6].

Marine Rhodobacteraceae are an important group of heterotrophic bacteria in the marine environment. They are known under the operational term "Roseobacter group" [7] and their phages are known as roseophages. Marine Rhodobacteraceae show high metabolic versatility, metabolize a wide variety of organic compounds, degrade dimethylsulfoniopropionate, perform anoxygenic photosynthesis and produce various secondary metabolites [7-9]. Rhodobacteraceae are present in diverse marine habitats (pelagic, sediment, surface-associated) and are most abundant in coastal temperate to polar regions [10-13]. Members of 
Rhodobacteraceae typically increase in abundance during algal blooms, where they dominate the active bacterial community, utilize algal exudates and lysates and potentially engage in both mutualistic and pathogenic interactions with the algae [14-18]. Amongst the roseobacters, Lentibacter is a genus relevant in coastal and estuarine waters, where its relative abundance can be up to $30 \%$ of the bacterial community [19], and has been repeatedly isolated from algal blooms in different geographical locations [20, 21].

In contrast to the large diversity of marine Rhodobacteraceae, which includes currently over 70 genera [22], only a few roseophages, infecting seven genera, have been isolated so far. More than half of the cultivated roseophages belong to the N4-like phage group [23-28] and recent taxonomic reevaluation suggests that they likely form a subfamily within Podoviridae [29]. Other roseophages have been classified in the Podoviridae or Siphoviridae families [30-38].

The SIO1 phage infecting Roseobacter sp. SIO67 was the first described roseophage and the first sequenced marine phage [30]. Highly similar phages ( $>96 \%$ nucleotide identity) were isolated twelve years later from the same geographic area, providing evidence that marine viruses can exist as discrete populations over long periods of time [39]. The SIO1 phage belongs to the Podoviridae and is distantly related to the T7 phage [30], but has no RNA polymerase. A close relative of SIO1 is the roseophage P12053L infecting Celeribacter marinus IMCC12053 [33, 40]. Hardies et al. [41] assigned SIO1 and Vibrio phage VpV262 to a T7 supergroup. This supergroup includes T7 related phages with an RNA polymerase (the Autographivirinae subfamily), and also phages without the RNA polymerase. Hardies et al. [40] showed that all podoviruses, except those in the Picovirinae subfamily, have a tail structure related to $\mathrm{T} 7$ and propose their placement within the transient tail structural homology group, with the following subgroups: the $\mathrm{T} 7$ subgroup (the Autographivirinae), the epsilon15 subgroup, the phage RIO-1 subgroup (including SIO1 phage), the P22 subgroup, the N4 subgroup, and a new subgroup represented by Pseudomonas phage F116.

In this study, two novel roseophage species infecting Lentibacter sp. SH36 were isolated and sequenced. The recruitment from sequence data sets of similar genomes, including that of SIO1 and of environmental phages, has led to the delineation of a new group of phages which we termed the "Cobavirus" group. Furthermore, we carried out a comprehensive analysis of the phylogeny, classification, genomic organization, host range and ecology of the Cobavirus group, infecting also two other roseobacter genera. A survey of its global biogeography showed that cobaviruses occur mainly in coastal but also in oceanic water masses from temperate to tropical oceans.

\section{Materials and methods}

\section{Phage enrichments and isolation of ICBM1 and ICBM2 phages}

Surface seawater was collected from multiple stations (53.978 8.059; 53.937 7.806; 53.896 7.535; 53.840 7.255; $53.7936 .997)$ in the southern North Sea, during a phytoplankton bloom in March 2015, on board of the cruise ship RV Heincke. Further, the seawater from each station was filtered on board through $0.7 \mu \mathrm{m}$ filters, $47 \mathrm{~mm}$ in diameter (GTTP filters, Millipore). To prevent clogging, the filters were exchanged every 2 liters. The seawater from all stations was pooled, transported to the laboratory and stored at $4{ }^{\circ} \mathrm{C}$ in the dark. Two phage enrichments (S1 and S2), each of $100 \mathrm{ml}$, were set up by mixing $90 \mathrm{ml}$ of freshly filtered (Nalgene rapid-flow, $0.2 \mu \mathrm{m}$, PES membrane, ThermoScientific) seawater with $10 \mathrm{ml}$ of $10 x$ ASW (see SI file S1 text) and $2.1 \mathrm{ml}$ of exponentially growing host culture Lentibacter sp. SH36 (final $\mathrm{OD}_{600}=0.006$ ). Two controls were prepared in parallel. The first, a positive control (PC) for host growth, consisted of $100 \mathrm{ml} 1 \mathrm{x}$ ASW and $2.1 \mathrm{ml}$ of exponentially growing host culture (final $\mathrm{OD}_{600}=0.006$ ). The second, a negative control (NC) for growth of seawater bacteria contaminants, which might have passed through the $0.2 \mu \mathrm{m}$ filter, consisted of $90 \mathrm{ml}$ freshly filtered $(0.2 \mu \mathrm{m})$ seawater and $10 \mathrm{ml} 10 \mathrm{x}$ ASW. Bacterial growth was monitored by measuring the optical density at $600 \mathrm{~nm}$ (Beckmann DU520, USA). The cultures were incubated at $20^{\circ} \mathrm{C}$ and $100 \mathrm{rpm}$ overnight, until the enrichment cultures showed signs of cell lysis. Lysis was indicated by decreasing OD in S1 and S2 cultures compared to the positive control and by the presence of cell debris in $\mathrm{S} 1$ and S2. The cell free phage lysates from the S1 and S2 enrichments were used to isolate the ICBM1 and ICBM2 phages, respectively, by plaque assays and single plaque picking. To determine the host range, 94 strains (SI file S1 Table S1) covering the phylogenetic diversity of Rhodobacteraceae were challenged with ICBM1 and ICBM2 phages, at three different temperatures $\left(15,20\right.$, and $28^{\circ} \mathrm{C}$ ), using the spot and plaque assay. For long-term storage, the phages were infected into the host cells (before cell lysis), resuspended in glycerol and kept at $-80^{\circ} \mathrm{C}$. Further details on phage isolation, host range determination and long-term storage procedures are found in SI file S1 text.

\section{ICBM1 and ICBM2 phage lysates}

To obtain a high amount of ICBM1 and ICBM2 phage biomass for TEM and genome sequencing, two subsequent infection cultures of Lentibacter sp. SH36 with phage ICBM1 or ICBM2 were performed. For the first round of infection, 1x ASW was inoculated with exponentially 
growing Lentibacter sp. SH36 to a final $\mathrm{OD}_{600}$ of 0.006 and with phage ICBM1 or ICBM2 stock. After an overnight incubation at $20^{\circ} \mathrm{C}$ and shaking at $100 \mathrm{rpm}$, lysis was observed, indicated by a decrease in the $\mathrm{OD}_{600}$ (in comparison with the control, non-infected culture) and cellular debris. The remaining cells and cell debris were removed by centrifugation $\left(15 \mathrm{~min}, 4,000 \mathrm{xg}, 20^{\circ} \mathrm{C}\right)$ and $0.22 \mu \mathrm{m}$ filtration. For the second round of infection, a highly concentrated phage-host mixture was obtained by pelleting an exponentially growing culture of Lentibacter sp. SH36 and re-suspending the cell pellet in the phage fraction from the first infection culture. After the phage-host mixture was incubated on ice for $15 \mathrm{~min}$ to facilitate phage absorption, an equal volume of $2 \mathrm{x}$ ASW was added to it and the infection culture incubated overnight at $20^{\circ} \mathrm{C}$ and $100 \mathrm{rpm}$. After lysis, the phage fraction was obtained by centrifugation $(15 \mathrm{~min}, 4,000 \mathrm{x} g$, $20^{\circ} \mathrm{C}$ ) and $0.22 \mu \mathrm{m}$ filtration to remove remaining cells and cell debris.

\section{Transmission electron microscopy}

ICBM1 and ICBM2 phages were purified by $\mathrm{CsCl}_{2}$ centrifugation. Two staining procedures were performed for each phage prior to transmission electron microscopy (TEM): (1) ammonium molybdate staining and (2) uranyl acetate staining, see SI file S1 text for details. Phages negatively stained by uranyl acetate were used for capsid size measurements.

\section{Isolation and purification of phage DNA for sequencing}

\section{Phage isolates - extraction of DNA from virions}

Phage DNA was extracted from cell free phage lysates obtained by infecting Lentibacter sp. SH36 with ICBM1 or ICBM2. The phage fraction was concentrated by polyethylene glycol precipitation, treated with DNase to remove free, chromosomal DNA, and then phage DNA was purified using the ChargeSwitch gDNA Mini Bacteria Kit (ThermoFisher Scientific). For details, see SI file $\mathrm{S} 1$ text.

\section{Phage enrichments - extraction of DNA from the intracellular phage fraction}

Cells from the S1 and S2 enrichments and from the PC culture were collected when cell lysis was detected in S1 and S2. As expected, the NC culture showed no growth. Cells were embedded in agarose, digested to remove the proteins and lipids, and the phage DNA was separated from the chromosomal DNA by agarose gel electrophoresis. The phage DNA fraction in S1 and S2 was identified by comparison with DNA from the PC culture (Fig. 1c), and phage DNA was extracted from the gel, purified and sequenced. For details, see SI file S1 text.

\section{Genome sequencing and assembly}

The ICBM1 phage and the S2 enrichment were sequenced using both Illumina (paired-end technology $2 \times 300 \mathrm{bp}$ ) and PacBio technologies. The ICBM2 phage and the S1 enrichment were sequenced only by Illumina. The Illumina and the PacBio assemblies were performed separately and they resulted in identical phage genomes (SI file S1 Table S2). Error free assembly of the PacBio samples was possible due to the high coverage obtained $(>4,000 x)$. The phage genomes are available in the NCBI GenBank database under the following accession numbers: MF431617 (ICBM1), MF431616 (ICBM2) and MF431615 (ICBM3, assembled from the S2 phage enrichment). For details about sequencing and assembly, see SI file S1 text.

\section{Retrieval of phage genomes related to ICBM1 and ICBM2}

The following datasets were queried for sequences related to ICBM1 and ICBM2: (i) the Tara Ocean Viromes [4], (ii) the Earth Virome [5], (iii) the Global Ocean Virome [3], (iv) the IMG/VR [42] and (v) the Environmental Viral Genomes [6]. The Tara Oceans Viromes (assembled DNA contigs and predicted proteins) and Global Ocean Virome datasets were downloaded from the iVirus (http://ivirus.us/ [43],) using the CyVerse platform and its Discovery Environment (https://de.cyverse.org/de/ [44],). The Earth Virome dataset (assembled DNA contigs) was downloaded from http://portal.nersc.gov/dna/microbial/ prokpubs/EarthVirome_DP/. The downloaded datasets were imported in Geneious 9.1.5, transformed in BLAST databases and queried by megaBLAST (e-value $1 \mathrm{e}^{-5}$ ), using the ICBM1 and ICBM2 genomes and by BLASTp (e-value $1 \mathrm{e}^{-5}$ ) using the portal and terminase proteins of the ICBM1, ICBM2, SIO1 (only the terminase protein was used) and P12053L phages. The IMG-VR viral sequence database was queried by BLASTn (e-value $1 \mathrm{e}^{-5}$ ) webservice offered at https://img.jgi.doe.gov/cgi-bin/vr/ma in.cgi, using the ICBM1 and ICBM2 genomes. The proteins retrieved by Blastp were added to the databases of terminase or portal proteins from known phages, followed by multiple alignment with Muscle and calculation of phylogenetic trees with FastTree v 2.1.5 [45]. Further, the proteins in the vicinity of ICBM1, ICBM2, SIO1 and P12053L were selected, and their corresponding contigs retrieved. These contigs were pooled with all those retrieved by nucleotide 


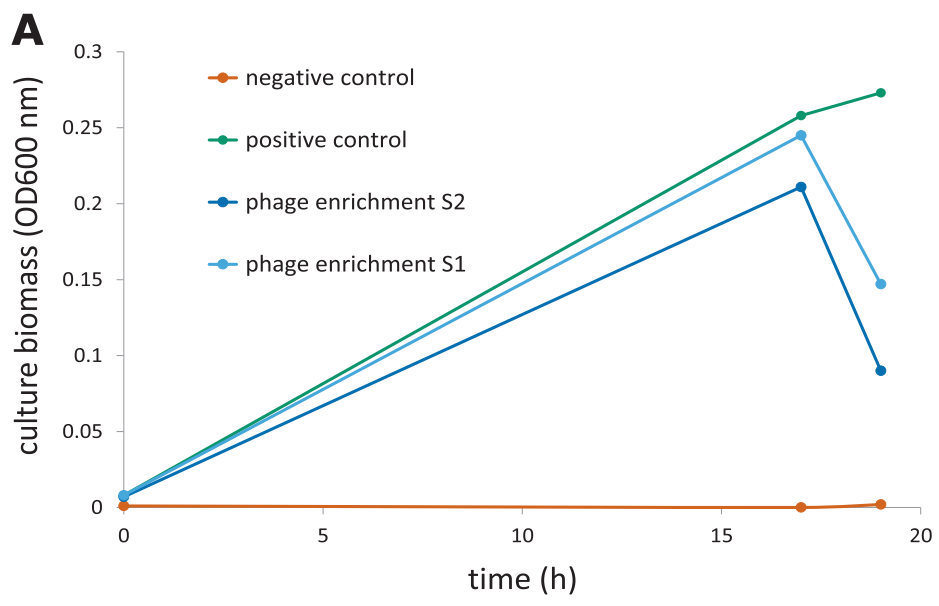

B
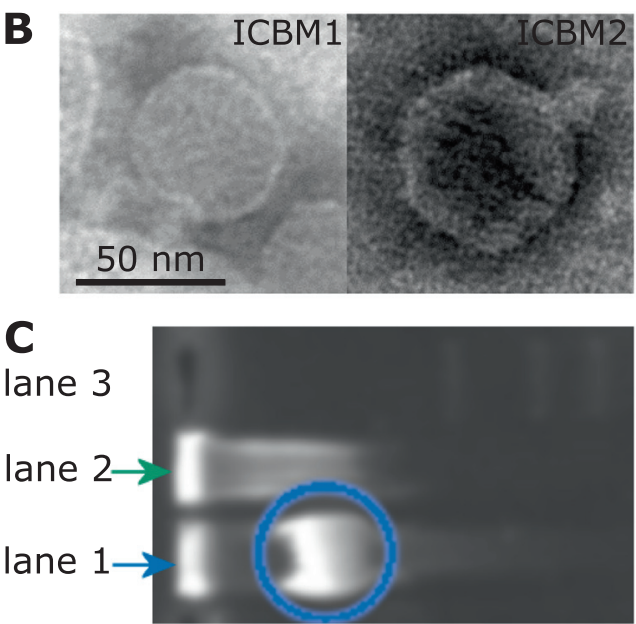

Fig. 1 a. Enrichment of phages specific for Lentibacter sp. SH36 from North Sea water. The experimental setup consists of: (i) Phage enrichments (blue lines) - logarithmic phase cells added to nutrient amended, $0.2 \mu \mathrm{m}$ filtered seawater, (ii) Positive control for cell growth (green line) - logarithmic phase cells added to artificial seawater and (iii) Negative control (orange line) - only nutrient amended, $0.2 \mu \mathrm{m}$ filtered seawater, no cells added. In the S1 and S2 enrichments the decrease in OD at $18 \mathrm{~h}$ is most likely due to phage cell lysis. No

Blast. All contigs smaller than $34 \mathrm{kbps}(\sim 85 \%$ of the ICBM1 genome length) were considered incomplete and removed.

\section{Genome-based phylogeny and classification}

To reconstruct the whole genome-based phage phylogenetic tree, a set of genomes comprising all podoviral genomes recognized by the International Committee of Taxonomy of Viruses (ICTV) was supplemented with the cobavirus-related genomes retrieved from the different public sequence datasets (see above). For consistency, open reading frames (ORFs) for the complete set of genomes were detected using MetaGeneAnnotator [46], which was implemented in the VirSorter program [47]. Using the Virus Classification and Tree Building Online Resource (VICTOR [48], available at https:// victor.dsmz.de), all pairwise phage comparisons of the amino acid sequences were conducted via the underlying GenomeBLAST Distance Phylogeny (GBDP) method [49] under settings recommended for prokaryotic viruses [48]. The resulting intergenomic distances (including 100 replicates each) were used to infer a balanced minimum evolution tree with branch support via FASTME including SPR postprocessing [50] for each of the formulas $d_{0}, d_{4}$, and $d_{6}$. The trees were rooted at the midpoint [51] and visualized with iTOL [52]. Taxon boundaries at the species, genus, subfamily and family level were estimated with the OPTSIL program [53] using the recommended clustering thresholds [49] and an $F$ value (fraction of links required for cluster fusion) of 0.5 [54]. growth was detected in the negative control. b. Transmission electron micrograph of molybdenum stained, cell debris bound Lentibacter virus vB_LenP_ICBM1 and uranyl acetate stained, free Lentibacter virus vB_LenP_ICBM2. Scale bar: $100 \mathrm{~nm}$. c. Agarose gel electrophoresis of cellular DNA from i) Lentibacter sp. SH36 phage infected cells, S2 enrichment (lane 1, blue arrow) and ii) not infected cells, positive control for cell growth (lane 2, green arrow). Blue circle: intracellular phage DNA. Lane 3: $1 \mathrm{kbp}$ Plus DNA Ladder

\section{Genome annotation and protein clustering}

All phage genomes compared in this study, including the already published ones, were re-annotated using the same procedure to eliminate differences resulted from different annotation pipelines. Initially, ORFs were detected using MetaGeneAnnotator [46] implemented in VirSorter [47]. Proteins were then annotated by comparing them with several databases and manually deciding the final annotations. The NR database (http://ncbi.nlm.nih.gov/) was queried using Protein-Protein BLAST 2.6.0+, the InterPro database v66.0 [55] was queried using InterProScan 5.27-66.0 tool [56], and the prokaryotic viruses orthologous groups database [57] was queried using hmmscan command from HMMER $3.1 \mathrm{~b} 2$ package [58]. The proteins were clustered by first performing an all against all BlastP, with an e-value threshold of $1 \mathrm{e}^{-5}$ and a bitscore threshold of 50, and the results were inputted into the mcl program, with the parameters "-I 2 --abc". The online tool tRNAscan-SE v. 2.0 (http://lowelab.ucsc.edu/ tRNAscan-SE/index.html [59],) was used for tRNA prediction. Rho-independent terminators were predicted with ARNold http://rna.igmors.u-psud.fr/toolbox/arnold/index. php. Only the terminators with deltaG higher than 10.5 were considered. Details of genome features, protein clusters and DNA sequences for all cobaviruses identified are listed in SI file S2 and S3. The comparative genome map was generated using the genoPlotR package [60] from the $\mathrm{R}$ programming environment (https://www.rproject.org/). 


\section{Phylogenetic analyses of single proteins}

Phylogenetic trees were constructed for the terminase protein, to gain insights about the genome ends. Phylogenetic analysis of spanin, glutaredoxin and cobalamin dependent ribonucleotide reductase (RNR) proteins was conducted to find insights about the hosts of the environmental cobaviruses and their habitat. Proteins were aligned with Muscle, and then phylogenetic trees were constructed using the FastTree v 2.1.5 program [45] integrated as a plugin in Geneious v 9.1.5 (http://www.geneious.com [61]), using default parameters. Phylogenetic trees were visualized using FigTree v1.4.3. ([62], available at http://tree.bio.ed.ac.uk/ software/figtree/).

\section{Phylogenetic analysis of the host rRNA}

The 16S rRNA gene phylogenetic tree was constructed using the ARB software package (www.arb-home.de/ version arb-6.0.2) [63]. Sequences of the type material $(>1,300$ bp) were used for the backbone-tree using the neighbor joining method with 1500 replicates. Shorter sequences used in this study were added afterwards by parsimony interactive without using a filter.

\section{Biogeographic distribution of cobaviruses and read mapping}

\section{Metagenomic data sets, download and preprocessing}

The unassembled datasets used for read mapping were downloaded from the European Nucleotide Archive (ENA, https://www.ebi.ac.uk/ena). A complete list of datasets used is given in SI file S4. The Tara Ocean survey datasets have been cleaned before their deposition at ENA [64], and thus, we used them as such for read mapping. We cleaned the remaining datasets using BBDuk from the BBTools package (BBTools (https://jgi.doe.gov/data-and-tools/bbtools/), as follows: (i) reads corresponding to the Enterobacteria phage phiX174 were filtered out; (ii) sequences of Illumina adapters and primers as provided in the BBTools package were removed $(\mathrm{ktrim}=\mathrm{r} \mathrm{k}=21 \mathrm{rcomp}=\mathrm{t} \operatorname{mink}=11$ hdist $=1$ tpe tbo); (iii) low quality (quality value lower than 20) nucleotides from both read ends were removed and reads with low average quality $(<20)$ or short length $(<30$ bases) were also removed ( trim $=\mathrm{rl}$ trimq $=20 \mathrm{ftm}=5$ maq $=20$ minlen $=30$ ). Quality control of the cleaned samples was performed on a subset of random samples, using FastaQC. The metadata associated with the metagenomes were retrieved from the NCBI site, BioSamples databases. In specific cases, if metadata were missing, we received them by direct contact with the principle investigators for the respective projects.

\section{Read mapping}

BBMap from the BBTools package was used to map the reads from the unassembled datasets to the cobaviral genomes. The output was sent to Samtools View and then to Samtools Sort to produce a sorted bam file. A phage was considered to be present in a particular sample when at least $75 \%$ of its genome was covered by reads with at least $90 \%$ identity, as previously determined [65]. The relative abundance of a phage genome in a sample was calculated by the following formula: "number of bases at $\geq 90 \%$ identity aligning to the genome / genome size in bases / library size in gigabases $(\mathrm{Gb})$ ". All code used for read mapping and data analysis are available in SI files S7a-d.

\section{Results and discussion}

\section{Isolation and host range of two Lentibacter sp. SH36 viruses}

Two strictly lytic bacteriophages, Lentibacter virus vB_LenP_ICBM1 (ICBM1) and Lentibacter virus vB_LenP_ICBM2 (ICBM2) were isolated to pure cultures from phage enrichments S1 and S2, respectively (Fig. 1a). The phage source in the enrichments was surface seawater collected during a March 2015 algal bloom in the southern North Sea. The host was Lentibacter sp. SH36, which was isolated from a seawater sample taken on 12 May 2007 in the southern North Sea during a phytoplankton bloom [21]. ICBM1 and ICBM2 phages negatively stained with uranyl acetate had isometric capsids with hexagonal cross-sections of $58.7 \pm 3.7 \mathrm{~nm}$ (sample size $=100$ phages) and $59.2 \pm 2.8 \mathrm{~nm}$ (sample size $=$ 100 phages), respectively, and short tails (Fig. 1b). Assessment on 94 Rhodobacteraceae strains (SI file S1 Table S1) showed that ICBM1 and ICBM2 have a narrow host range, infecting only Lentibacter sp. SH36.

\section{Sequencing the phage isolates and enrichments}

To gain insights into the diversity of the phage enrichments, we sequenced both the purified phages (ICBM1 and ICBM2) and the intracellular phage fraction of the enrichments (Fig. 1c, SI file S1 Table S2).

From the S2 enrichment two complete phage genomes were assembled, that of ICBM2 and of a third phage. The latter had $99.6 \%$ sequence similarity at nucleotide level with ICBM1 (under VICTOR formula $d_{0}$ see SI file S6) and was named Lentibacter virus vB_LenP_ICBM3 (ICBM3). Both ICBM1 and ICBM3 have been assembled twice, once from Illumina and once from PacBio reads, with identical results (SI file S1 Table S2). Therefore, differences between them were real and not due to sequencing errors. According to the 
VICTOR [48] results, ICBM1 and ICBM3 formed a species cluster, whereas ICBM2 represented a distinct species (see section below and Fig. 2).

From the S1 enrichment we retrieved an ICBM3-like genome $(99.9 \%$ identical with ICBM3, differences potentially due to sequencing errors, see SI file S1 Figures S1 and S2). Read mapping with a cutoff of $100 \%$ read identity showed that both ICBM1 and ICBM3 were present in S1 (Table 1, SI file S1 Figure S2). The presence of both ICBM1 and ICBM3 phages in the S1 enrichment is strengthened by the isolation of ICBM1 from this enrichment and it indicates microdiversity. Microdiversity in phage enrichments have been previously reported [66] and it potentially reflects the situation in the original seawater.

Using a 95\% read identity cutoff for mapping, all reads in the enrichments recruited either to the ICBM1/ ICBM3 or to the ICBM2 genomes (Table 1). This indicates that, without considering microdiversity, most likely no other phage was present and our isolation efforts retrieved the complete phage diversity in the enrichments at the species level.

\section{Retrieval of similar phage genomes and phylogenetic positioning}

Cultivated and environmental phage genomes similar to ICBM1 and ICBM2 were found in public sequence data sets. The related cultivated phages were P12053L infecting Celeribacter marinus IMCC12053, SIO1 infecting Roseobacter sp. SIO67 and four other SIO1 related strains, infecting Roseobacter sp. SIO67 and Roseobacter sp. GAI-101 [39]. From the environmental genomes, only those bigger than 35 kbp were considered for further analysis (see Table 2 and SI file S1 text). These were JGI26117J46588_1000006, JGI26119J46589_1000020, Ga0075461_10000015, DelMOWin2010_c10000155, JGI25132J35274_1000025, Tp1_124_ DCM_0_0d2_scaffold2117_1, which we chose to identify in this manuscript as EnvX, EnvY, EnvZ, Env8, Env9 and Env14, respectively.

The VICTOR method [48] for phage phylogeny and classification was used because it is universal and allows for an informed decision on the evolutionary relationships between prokaryotic viruses. The method was thoroughly optimized against a large reference dataset of genomesequenced taxa recognized by the International Committee on Taxonomy of Viruses (ICTV) and showed a high agreement with the classification, particularly at the species and genus level.

The genome-based VICTOR [48] phylogeny combined with taxon boundaries prediction based on OPTISIL [53] showed that the Lentibacter sp. SH36 phages (ICBM1, ICBM2 and ICBM3), together with SIO1, P12053L and some of the environmental genomes formed a highly supported genus level clade (Fig. 2). This proposed genus was tentatively named here as Siovirus (from the SIO1 phage) (Fig. 2). Most of the sioviruses had a class II, cobalamin dependent RNR and were placed within one cluster, which we called the Cobavirus (cobalamin-dependent) group. Two of the environmental sioviruses had a class I RNR and formed a separate clade. RNRs are used to convert host ribonucleotides in deoxyribonucleotides necessary for phage replication. Because the RNR class is predictive of the phage habitat [67] and class II RNRs point toward an association with phototrophic protists, we focused further on the Cobavirus group, which included all cultivated and part of the environmental sioviruses (Fig. 2).

In agreement with previous findings for the SIO1 and P12053L phages [40], the cobaviruses clustered within the RIO-1 subgroup (Fig. 2). The OPTISIL based taxon boundaries reported by VICTOR [48] suggested that the RIO-1 subgroup forms a maximally supported group, which we propose to define as a new subfamily in the Podoviridae, and tentatively named here Riovirinae (from the RIO-1 phage).

We have excluded the ICBM3 phage from further analysis, due to its high similarity with ICBM1 (Fig. 2 and SI file S1 Figure S6) and the phages SIO1_2001, OS, MB, SBRSIO67, because their genomes contained several regions of sequence uncertainty (long stretches of Ns).

\section{Genomic organization}

\section{Genome termini}

Within the proposed subfamily Riovirinae, the genome ends of the VpV262 and RIO-1 phages have been characterized and consist of direct terminal repeats (DTRs) [41, 68]. The SIO1 phage was reported to have inverted repeats [30], and no information was available for P12053L. We used coverage information and read structure from genome sequencing to determine the termini of the ICBM1, ICBM2 and ICBM3 phages. The Illumina reads were not informative regarding the genomic ends, as expected for sequencing libraries prepared with the NexteraXT kit [69]. On the other hand, the PacBio reads clearly showed the presence of short DTRs (159-173 bp) at the genome ends of all three phages (SI file S1 text).

We further investigated the ends of the other cobaviral genomes. The ends of SIO1 were originally determined after whole genome sequencing through a combination of shotgun cloning and Sanger technology. Inverted repeats ( 251 to 637 bases) detected at the ends were presumed to be involved in replication [30]. Our own analysis indicated that the ends were most likely placed incorrectly, probably due to low read coverage. Several facts supported our conclusion. First, in phylogenetic trees for the terminase gene, the phages ICBM1, ICBM3 and SIO1 grouped closely (SI 

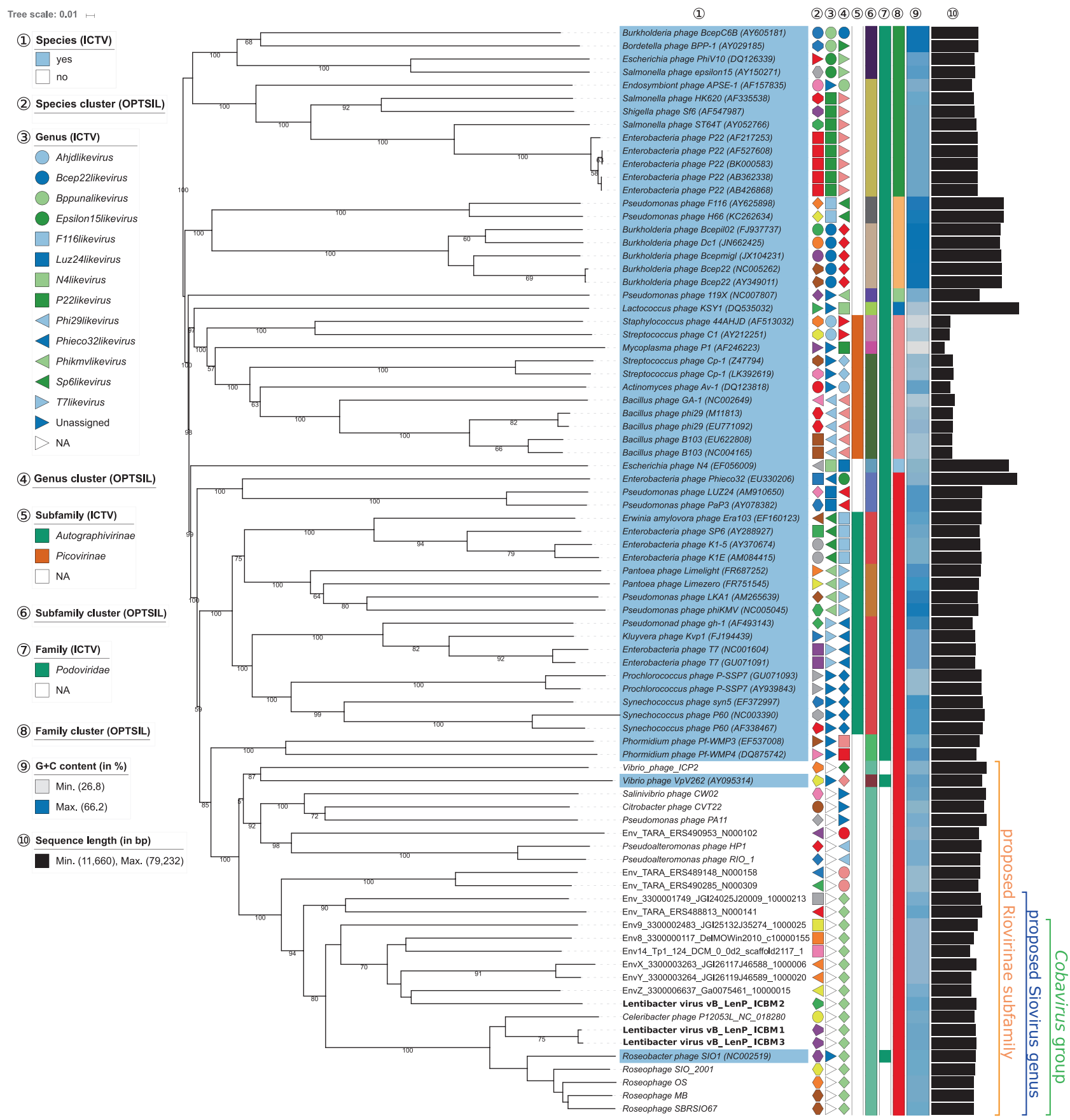

Fig. 2 Phylogenetic positioning of the Lentibacter sp. SH36 viruses and their relatives within the Podoviridae. The whole-genome-based phylogeny was inferred using the Genome-BLAST Distance Phylogeny method implemented in the VICTOR web service, using the amino acid data. Internal branch labels represent pseudo bootstrap support values if larger than $50 \%$. The proposed subfamily Riovirinae, the proposed genus Siovirus and the Cobavirus group (sioviruses with cobalamin-dependent RNR) are annotated at the right-hand side. Further information regarding the affiliation of phages to ICTV taxa

file S1 Figure S7), indicating that they likely have similar genome packaging strategies [70]. Second, re-sequencing of the SIO1 genome did not retrieve the complete region of the inverted repeats [39]. This was initially attributed to and OPTSIL clusters as well as $\mathrm{G}+\mathrm{C}$ content and genome sizes is described within the figure legend (circled numbers). "Viruses annotated as "Unassigned" in legend "Genus (ICTV)" have been assigned to both an ICTV species and family but not to a genus level, whereas "NA" refers to viruses which have not been recognized as a taxa by the ICTV. The affiliation of one or more viruses to a distinct species, genus, subfamily or family cluster is indicated by a specific symbol of same shape and color

difficulties in PCR amplification of the repeats. On the other hand, the lack of retrieval can also suggest misassembly of the original genome sequence in this region. Third, from the three inverted repeats, none were placed at the exact ends of 


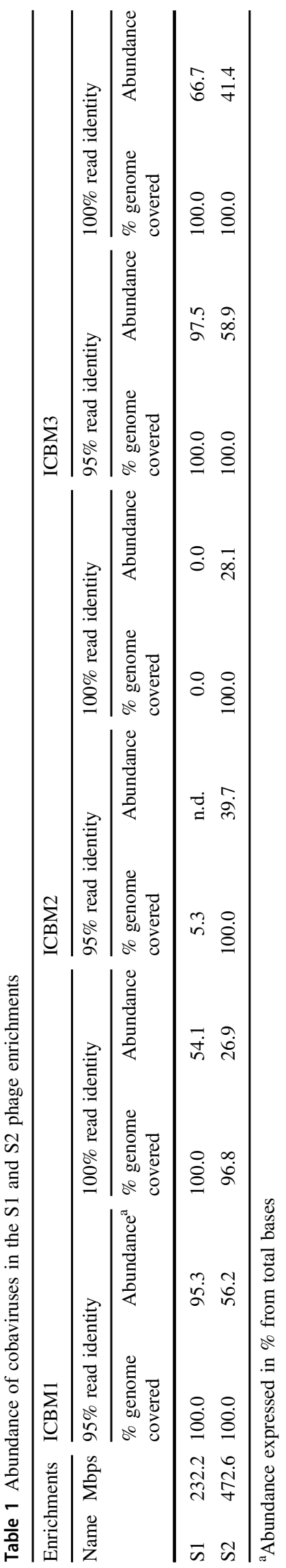

the genome and two of the inversions were located at the same end (SI file S1 Figure S8). Inverted terminal repeats at the genome ends are found in viruses which replicate by a protein-primed mechanism, where they are positioned at the exact ends of the genomes [71, 72]. Hence, it is unlikely that the three inverted repeats of the SIO1 phage have a role in replication. Fourth, in its original order the SIO1 genome shows an ORF free region exactly in between two gene modules (SI file S1 Figure S8), a region which shares high sequence similarity ( $\sim 80 \%$ identity) with the DTRs from ICBM1 and ICBM3 phages (SI file S1 Figure S9). An inspection of podovirus genomes from public databases revealed that related phages can have DTRs with a nucleotide identity within the $70-100 \%$ range (SI file S1 Table S5). Therefore, we used the DTRs from ICBM1 to find the genome termini and rearrange the gene order accordingly, not only for the SIO1 phage, but also for the P12053L and environmental cobaviruses (SI file S1 text).

Our results show that the cultivated cobaviruses have DTRs. The presence of DTRs indicate that cultivated cobaviruses, similar to the $\mathrm{T} 7$ phage, most likely use long concatemeric DNA molecules as intermediates in replication and packaging, concatemers formed by the annealing of $3^{\prime}$ single strands resulted at the DTR level during replication $[73,74]$. The $5^{\prime}$ ends of all cobaviral DTRs have a conserved, $G+C$ rich region (SI file S1 Figure S9), underlining a potentially more important role of this region in genome circularization or replication, for example as enzyme binding site. The phylogenetic positioning in the GBDP-based VICTOR tree (Fig. 2) as well as in the terminase tree (SI file S1 Figure S7) suggests that the environmental cobaviruses also have DTRs and thus potentially the same DNA replication strategy.

\section{Gene composition and modular organization}

ICBM1 and ICBM2 phages had linear genomes of $\sim 40 \mathrm{~kb}$, a $\mathrm{G}+\mathrm{C}$ content of $\sim 47 \%$ (SI file S1 Table S3) and 58 and 55 ORFs, respectively. More than half of the ORFS coded for hypothetical proteins. No tRNAs were found. The genes were organized in two genomic arms, with opposite transcriptional directions and separated by a bidirectional, rhoindependent transcriptional terminator (Fig. 3 and SI file S1 Table S4). We found protein-encoding genes for replication and nucleotide metabolism on the left arm: two nucleases, a DNA polymerase, a dual primase/helicase, a cobalamin dependent RNR, a glutaredoxin, a ThyX thymidylate synthase (ThyX), a guanosine 3', 5'-bispyrophosphate (ppGpp) hydrolase (MazG) and a P-loop containing nucleoside triphosphate hydrolase $(\mathrm{PhoH})$ [75-80]. On the right genomic arm, we found genes for lysis and virion structure and morphology. Both phages had spanins, which were easy to recognize due to their specific architecture. At the $\mathrm{N}$ terminus the spanins had a lipoprotein domain for binding to 
the outer membrane. At the $\mathrm{C}$ terminus they had a transmembrane domain for binding to the inner membrane [81]. For endolysins, ICBM1 had a lysozyme-like protein and ICBM2 had an N-acetylmuramoyl-L-alanine amidase. The lysis genes were followed by genes for the internal virion proteins (IVP) B and D, a Gcn5-related N-acetyltransferase (GNAT), the tubular proteins $\mathrm{A}$ and $\mathrm{B}$, a major capsid protein, a scaffolding protein, a portal protein, a large terminase subunit, two tail fibers and three tail assembly chaperone proteins (see Fig. 3). With the exception of the endolysins, all other genes have been previously annotated in SIO1 or P12053L phages [30, 33, 39, 40, 81]. A previous study [82] annotated the gene for the pc40 protein from SIO1 as a long-chain fatty acid transporter (FadL) and thus listed it as AMG. However, our BlastP and InterProScan searches identified pc40 as a Gcn5-related N-acetyltransferases (GNAT). Based on the GNAT domain, pc40 could correspond to gp13 from T7, which is also positioned next to the internal virion proteins and has been suggested to play a role in virion morphogenesis [83].

Within the Cobavirus group, the genetic composition and synteny was mostly conserved (see Fig. 3). All genomes were organized in two arms, with genes for replication and nucleotide metabolism on the left and lysis and virion structure and morphogenesis on the right. This genomic organization was not previously reported for the SIO1 and P12053L phages, but it became evident once the genomes were rearranged according to the DTR positions (see section above and SI file S1 text). Furthermore, it appears in other members of the proposed Riovirinae subfamily, although the contained modules can vary $[68,84]$. Most cobaviruses had a bidirectional, rho-independent transcriptional terminator in between the two genomic arms, indicating a likely transcriptional separation (see Fig. 3). This type of terminator was shown to be functional in vitro for the Pf-WMP3 phage [85].

Most of the genes with a functional annotation in ICBM1 and ICBM2 phage were also found in all other cobaviruses, with the exception of glutaredoxin, ThyX and $\mathrm{PhoH}$, which were not found in some of the environmental cobaviruses (see Fig. 3). The endolysins were found in all cobaviruses, with the exception of EnvX and EnvY. They were free of membrane anchoring domains, indicating that cell lysis most likely proceeds via the canonical holin-endolysin pathway [86, 87]. The endolysins were diverse both in sequence and enzymatic function, encoding either lysozyme-like domains, or $\mathrm{N}$-acetylmuramoyl-L-alanine amidase or peptidase domains. The spanin was found in all cultured cobaviruses, and only in two of the environmental genomes, Env9 and Env8. In the vicinity of the spanin and endolysins genes we found several genes encoding one or two transmembrane domains, representing potential holins and antiholins (see Fig. 3).

In agreement with cobavirus phylogenetic positioning and virion morphology revealed by TEM (Fig. 1b), the 


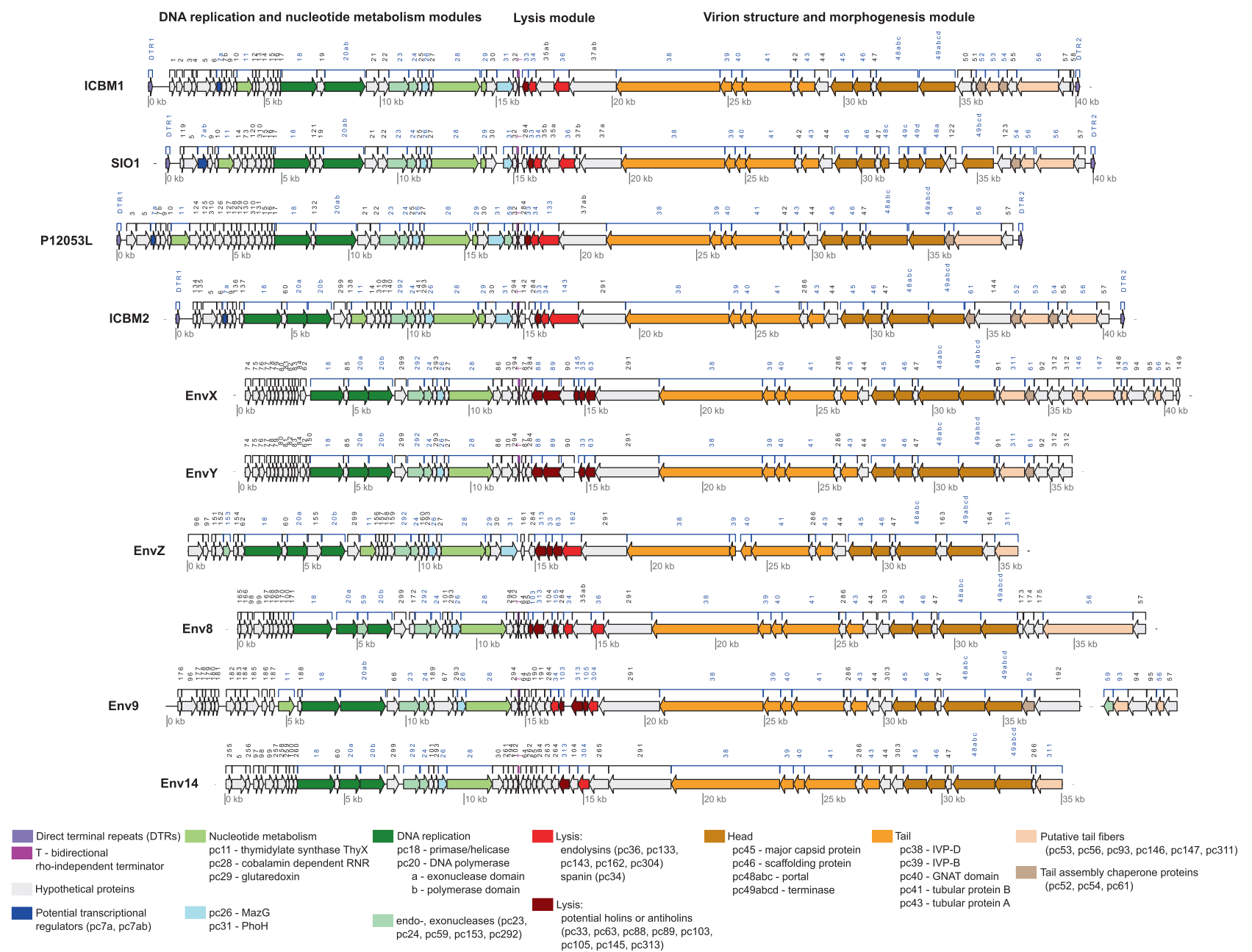

Fig. 3 Genome map of cultured and environmental Cobaviruses. The genomes are centered in the bidirectional rho-independent terminator. With the exception of EnvX and Env9, all other environmental genomes are incomplete, with sequence information missing at the two ends of the genomes (the host interaction and tail fibers modules). Blue numbers indicate protein clusters with functional annotation genes present in the virion structure and morphogenesis module most likely indicated a podoviral, T7-like virion structure [88-90]. A conserved genetic composition and synteny characterized the genomic region between the lysis module and the terminase gene (Fig. 3). The genomic region between the terminase and the $3^{\prime}$ end of the genome was variable both in gene count and composition and it encoded the proteins required for tail fibers, fiber connectors or tail assembly proteins. Most proteins were unique to a single phage or shared by a few. Some proteins (pc53, pc56, pc311) were similar to tail fibers or fiber connectors from myoviruses or siphoviruses, as noticed for other phages in the RIO-1 subgroup [40]. For example, pc53 resembled the short tail fiber protein from the T4 phage, a myovirus [91]. The pc56 protein was similar with the L-shaped tail fiber protein from the T5 phage and the T5-like siphoviruses DT57C and DT571/2 [92]. Therefore, the tail fibers of the cobaviruses likely depart from the simplicity of T7-like fibers, which are formed from a single protein (gp17) directly connected to the tubular protein $\mathrm{A}$.

\section{Cobaviral hosts}

The Cobavirus group contained both cultivated phages, with known hosts, and environmental phages, with unknown hosts. To have an up to date phylogeny of the hosts of cultivated cobaviruses, we built a $16 \mathrm{~S}$ rRNA gene-based tree (SI file S1 Figure S10). Our results showed that Roseobacter sp. SI067 belongs to the Lentibacter genus ( $>99 \%$ nucleotide identity with the type species) and Roseobacter sp. GAI-101 to the Sulfitobacter genus (>98\% nucleotide identity). Therefore, hosts of cultivated cobaviruses comprise members of the Lentibacter, Sulfitobacter and Celeribacter genera, within the Rhodobacteraceae family.

Furthermore, we searched for clues linking the environmental cobaviruses to potential hosts. A search in the CRISPR spacer database from IMG/VR returned no results, and no 
tRNAs where found within the cobavirus genomes. We found, however, three lines of evidence that point to environmental cobaviruses infecting members of the Rhodobacteraceae family. First, cobaviruses clustered into one genus, with nine out of 15 representatives known to infect Rhodobacteraceae members. According to Meier-Kolthoff and Göker [48], phage genera usually infect hosts within the same family. Second, all cobaviruses had a cobalamin-dependent RNR gene, encoding an enzyme used to reroute host resources toward phage replication. These phages need to infect bacteria able to synthesize cobalamin, and this ability is widespread within marine Rhodobacteraceae [93]. Genes involved in vitamin B12 synthesis are present in the two publicly available genomes from the cobaviral hosts. Additionally, in phylogenetic trees the RNRs from environmental cobaviruses clustered closely with ICBM2 (Fig. 4), whose host is Lentibacter sp. SH36. Third, all cultivated and two environmental cobaviruses (Env8 and Env9) had a spanin gene characteristic for roseophages. BLAST searches in the NR database from NCBI with the cobaviral spanins returned hits only from roseophages or members of Rhodobacteraceae, with the exception of one E. coli phage hit, which had very low similarity (Fig. 4a). This is not surprising, considering that spanins have little sequence homology to each other and Summer et al. [81] found no homolog for the SIO1 spanin. Using prophage prediction (PHASTER [94]), we determined that the spanins from Rhodobacteraceae genomes were present in putative prophage regions (SI file S1 Table S6). Therefore, phages infecting Rhodobacteraceae have similar spanins, another evidence that Env8 and Env9 most likely infect Rhodobacteraceae.

\section{Environmental distribution of the cobaviruses}

Cobaviruses have been isolated from three distinct coastal locations in the Northern Hemisphere: SIO1 from the American coast of the Pacific Ocean (Scripps Pier, California) [30, 39], P12053L from the Yellow Sea, South Korea [33] and ICBM1 and ICBM2 from the North Sea, Germany (this study). Sequences related to the SIO1 and P12053L phages were previously reported in predominantly coastal viromes from the North Pacific USA coast (Scripps Pier, British Columbia), the Gulf of Mexico, the Arctic Ocean, the North Atlantic (Chesapeake Bay and Sargasso Sea) and the Yellow Sea (Goseong Bay) [39, 95-98].

To further assess the environmental distribution, we queried for the presence of cobaviruses in more than 5,000 publicly available marine metagenomes, by mapping unassembled reads to cobaviral genomes. The queried metagenomes covered a wide range of marine environments, from coastal to open oceans, and from water column, to benthic, sediment and animal associated samples. All metagenomes from the Tara Ocean Expeditions [64] were included in the dataset, as well as the viromes from
Malaspina expeditions [99], along other marine datasets available in ENA in November 2017 (see SI file S4 for a complete list of all datasets used). We found cobaviruses in bonafide viromes and in metagenomes from cellular fractions, mostly in the prokaryotic range, but also in the small protist range (Fig. 5 and SI files S5). The presence of cobaviruses in cellular fractions could be explained by i) active infections at the time of sample collection, or ii) free phage particles retained on the large pore size filters by unspecific binding to the filter membrane or cell debris. A third explanation, the integration of cobaviruses in bacterial genomes as prophages, is unlikely, because, firstly, no cobaviral genes with functional annotations indicated a temperate life style. Secondly, although in phylogenetic trees using spanin cobaviruses were placed close to prophage regions from roseobacter genomes (Fig. 4a, SI file S1 Table S6), in whole genome trees cobaviruses were distant from these prophages (SI file S1 Figure S11).

Cobaviruses were detected in the euphotic water column, mainly close to coastal areas but also in the open ocean of the Pacific, Atlantic and Indian Oceans, as well as in the North Sea, the Mediterranean, the Adriatic, the Red Sea, the Arabian Sea, the Yellow Sea, the Salish Sea and in several estuaries (see Fig. 5a for an overview, SI file S5 for the list of coordinates and https://www.google.com/maps/d/viewer?mid= 1LlM8bT7MSHJIzYfUY2zneec4w0vSmXNO\&ll=17. $833079030938055 \% 2 C-6.043723249999857 \& z=2$ for $a$ detailed map). These waters span temperate to tropical regions. Hot spots for cobaviruses were in bays or estuaries, with several cobaviruses being detected in these locations, for example the Goseong Bay, Delaware Estuary and Chesapeake Bay (Fig. 5b and Table 3). This is consistent with a $16 \mathrm{~S}$ rRNA based survey, which retrieved known cobaviral hosts mainly from coastal areas (SI file S1 Figure. S12 andTables S4-10). Generally, abundance of cobaviruses was low. However, it increased markedly in the Port of Los Angeles samples (Fig. 5b, SI file S5), where roseophage SIO1, its related phages, and their respective host have been isolated [39].

Specific cobavirus strains are cosmopolitan, as revealed by the finding of specific genomes across distant geographical locations. For example, the ICBM1 and ICBM2 phages have been isolated from the North Sea, but similar phages have been found by read mapping in metagenomes from the Australian Coast (ICBM1), and from the Goseong Bay, Yellow Sea and the Port of Los Angeles (ICBM2, Figs. 5a, b). Similarly, environmental cobaviruses have been found by read mapping not only in the metagenomes from which they were originally assembled (Table 2 and Fig. 5a), but also in many other locations (Fig. 5b). The biogeographic distribution of the cobaviruses could be explained by passive transport by oceanic currents and local selection by environmental factors shaping host communities, as proposed for marine 


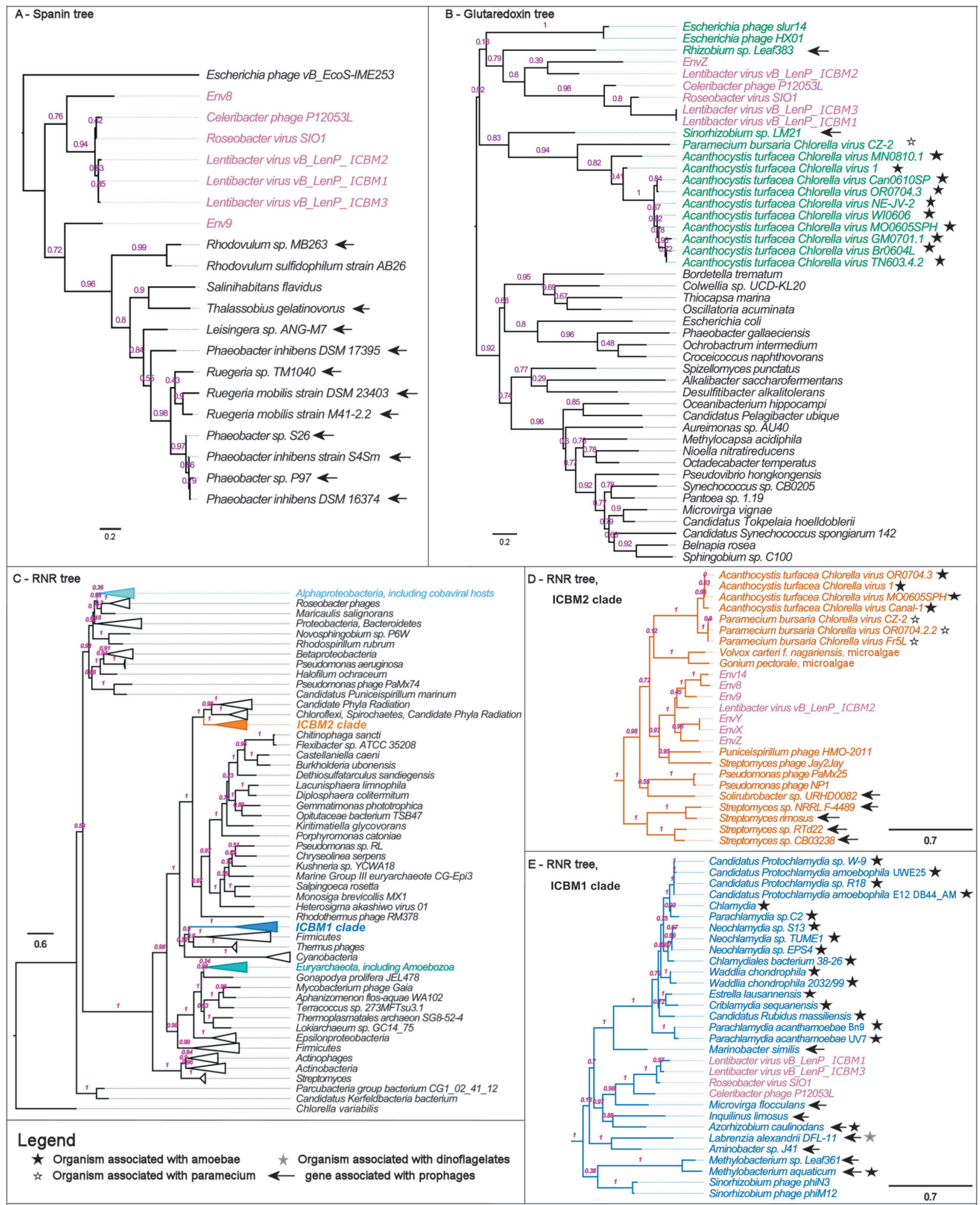

Fig. 4 Phylogenetic analysis of the spanin (a), glutaredoxin (b) and ribonucleotide reductase (c-e) genes from cobaviruses. The evolutionary history was inferred using the approximately-maximumlikelihood method implemented in FastTree 2.1.5. The node labels represent Fast Tree support values. The tree is drawn to scale, with branch lengths measured in number of amino acid substitutions per site. Association of the bacteria to eukaryotic organisms is indicated by stars. Location of the spanin, glutaredoxin or RNR genes in prophage regions, predicted with PHASTER [94], is indicated by arrows and further detailed in SI file S1 Tables S6, S11 and S12 

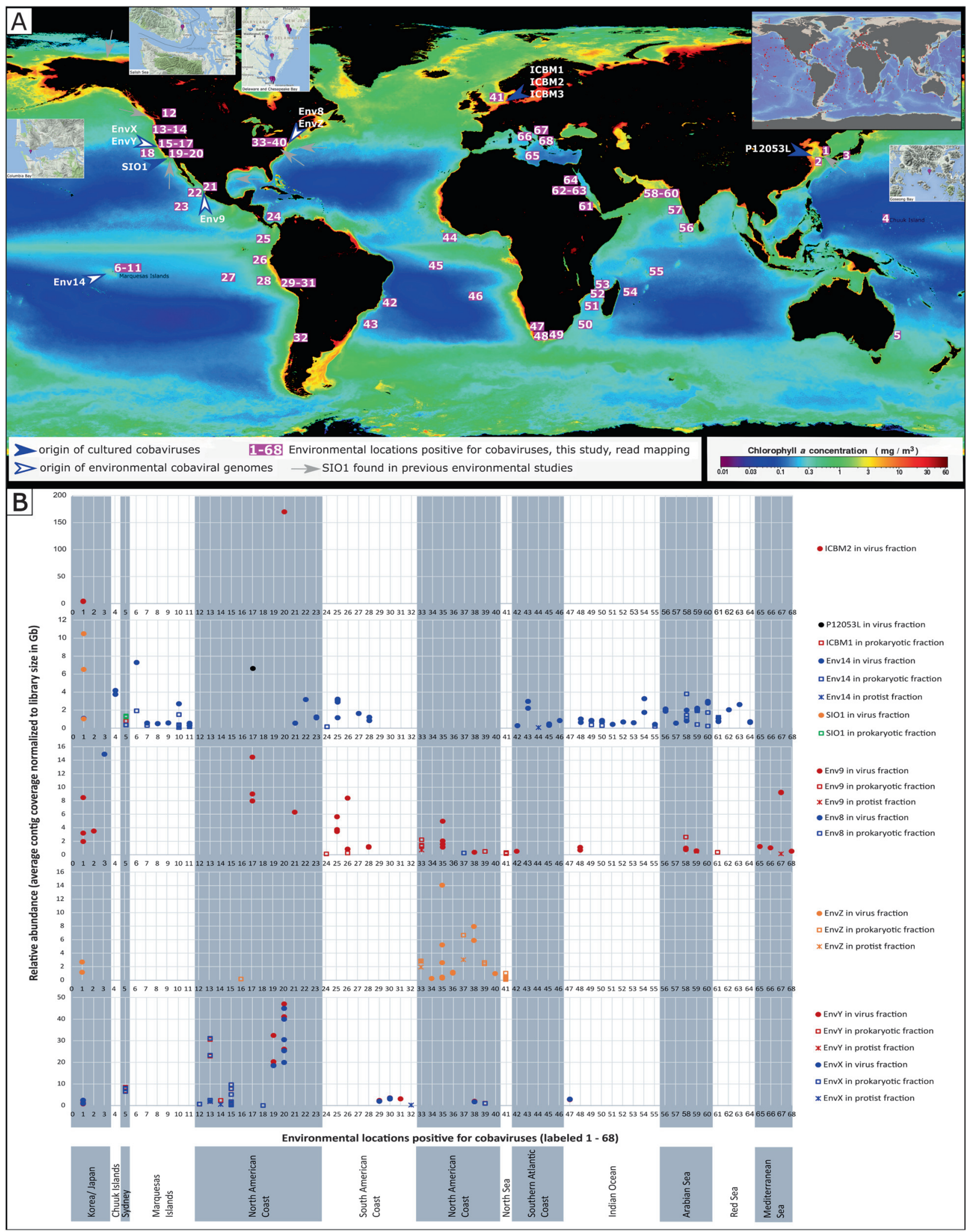

Fig. 5 Global distribution of Cobaviruses (a) and their abundance (average contig coverage per $\mathrm{Gb}$ metagenome) in metagenomic samples from marine environments (b). a (i) main map - each location were cobaviruses were found by read mapping in this study is labeled with a number, from 1 to 68; (ii) inset upper right corner - locations of all metagenomes searched in this study. Locations superimposed on an ocean chlorophyll concentration map (Aqua MODIS mission, 2010 annual composite, https://oceancolor. gsfc.nasa.gov/cgi/13 - NASA Goddard Space Flight Center, Ocean Biology Processing Group, 2014) 
viruses by Brum et al. [4]. In addition, considering that many positive locations for cobaviruses are also harbor areas, ship ballast water could contribute to virus transport across the oceans, in line with the findings by Kim et al. [100].

A few of the metagenomes positive for cobaviruses were part of sampling time series, allowing us to catch a glimpse of the cobaviral seasonality (see Table 3). In the North Sea, in metagenomic samples focused on spring/early summer algal blooms [16], EnvZ and Env9 were present in successive years, mostly post-bloom, but also before and during the blooms. In Goseong Bay [98] and Delaware Estuary, cobaviruses where present in early spring, late summer, fall and winter. This suggests that cobaviruses persist throughout the years in coastal environments.

\section{Protists as a habitat for the cobaviral hosts}

We used the search for cobaviruses in microbial metagenomes (see section above), as well as glutaredoxin and RNR trees, to find indications regarding the habitat of the cobaviral hosts. Cobavirus genomes were present in several metagenomes from the protist size fractions (Fig. 5b and SI file S5), suggesting that cobaviruses infect protist-associated bacteria. Most often cobaviruses were present in the $0.8-5 \mu \mathrm{m}$ fraction, which could arguably be contaminated with free living bacteria, but also in the $>3 \mu \mathrm{m}$ fraction (SI file S5), which makes it more likely that the bacterial cells present there were attached to or consumed by protists. The small protist size fraction is dominated by Alveolata, including dinoflagellates, followed by Rhizaria and Stramenopila [101], thus consisting of phagotrophic, parasitic and phototrophic species. Previous research [67] proposed that class II RNR-containing phages are infecting vitamin B12producing bacteria associated with phototrophic protists. This was based on the phylogenetic positioning of phage class II RNRs, including that of SIO1, next to chloroviruses (viruses of the single cell green alga Chlorella) and microalgae, and on the cobalamin requirement by the RNR. Other studies showed that marine Rhodobacteraceae can be associated with protists [102-105], including close relatives of the cobaviral hosts (SI file S1 SI Tables S7 and S8).

In our own analysis, the phylogenetic neighborhood of the cobaviral glutaredoxin and RNR (Figs. 4b-e) points toward a relationship of the cobaviral hosts not only with phototrophic protists, but also with phagotrophic/mixotrophic protists, as detailed further. Interactions with phagotrophs/mixotrophs, especially amoeba, but also paramecium and dinoflagellates, are a recurring theme in the RNR and glutaredoxin trees (Figs. 4b-e). For example, several organisms found in the vicinity of cobaviruses in both glutaredoxin and RNR trees are resistant to amoeba [106-109] and, most significantly, the Chlamydiae are well known endosymbionts or lytic parasites of amoebae [110]. Even the chloroviruses point towards amoeba or paramecium interactions, because they infect only
Table 3 Seasonal occurrence of cobaviruses in different locations

\begin{tabular}{|c|c|c|c|c|c|}
\hline Location & & Phage & Year & $\begin{array}{l}\text { Date (day. } \\
\text { month) }\end{array}$ & $\begin{array}{l}\text { Bloom } \\
\text { situation }\end{array}$ \\
\hline \multirow[t]{9}{*}{ Helgoland } & & EnvZ & 2010 & 11.05 & post bloom \\
\hline & & & & 18.05 & post bloom \\
\hline & & & 2011 & 28.04 & $\begin{array}{l}\text { in between } \\
\text { blooms }\end{array}$ \\
\hline & & & 2012 & 05.04 & post bloom \\
\hline & & & & 24.05 & post bloom \\
\hline & & & & 31.05 & post bloom \\
\hline & & & & 07.06 & post bloom \\
\hline & & Env9 & 2012 & 08.03 & pre bloom \\
\hline & & & 2014 & 20.06 & n.d. ${ }^{\mathrm{a}}$ \\
\hline \multirow[t]{14}{*}{ Goseong Bay } & & SIO1 & 2014 & 10.03 & n.d. \\
\hline & & & & 06.12 & n.d. \\
\hline & & VB2 & 2014 & 10.03 & n.d. \\
\hline & & EnvX & 2014 & 10.03 & n.d. \\
\hline & & & & 06.12 & n.d. \\
\hline & & EnvY & 2014 & 10.03 & n.d. \\
\hline & & & & 06.12 & n.d. \\
\hline & & EnvZ & 2014 & 10.03 & n.d. \\
\hline & & & & 06.12 & n.d. \\
\hline & & Env9 & 2014 & 10.03 & n.d. \\
\hline & & & & 08.09 & n.d. \\
\hline & & & & 20.09 & n.d. \\
\hline & & & & 06.12 & n.d. \\
\hline & & Env14 & 2014 & 10.03 & n.d. \\
\hline \multirow{12}{*}{$\begin{array}{l}\text { Delaware } \\
\text { Estuary }\end{array}$} & station 36 & EnvZ & 2015 & 11.04 & n.d. \\
\hline & station 37 & EnvZ & 2015 & 13.04 & n.d. \\
\hline & & Env8 & & & \\
\hline & station 38 & EnvX & 2015 & 11.04 & n.d. \\
\hline & & EnvY & & & \\
\hline & & EnvZ & & & \\
\hline & & Env9 & & & \\
\hline & station 39 & EnvX & 2015 & 15.04 & n.d. \\
\hline & & EnvY & & & \\
\hline & & EnvZ & & & \\
\hline & & Env9 & & & \\
\hline & station 40 & EnvZ & 2015 & 17.08 & n.d. \\
\hline \multirow{11}{*}{$\begin{array}{l}\text { Chesapeake } \\
\text { Bay }\end{array}$} & station 33 & EnvZ & 2014 & 01.11 & n.d. \\
\hline & & & & 03.11 & n.d. \\
\hline & & Env9 & 2014 & 22.03 & n.d. \\
\hline & & & & spring & n.d. \\
\hline & & & & 03.11 & n.d. \\
\hline & station 34 & EnvZ & 2014 & 30.08 & n.d. \\
\hline & station 35 & EnvZ & 2014 & 22.03 & n.d. \\
\hline & & & & 02.11 & n.d. \\
\hline & & & & 03.11 & n.d. \\
\hline & & Env9 & 2014 & 22.03 & n.d. \\
\hline & & & & 03.11 & n.d. \\
\hline
\end{tabular}

${ }^{a}$ n.d. $=$ not determined 
Chlorella strains that form endosymbioses with amoebae or paramecium [111, 112]. Amoebae themselves have a functional cobalamin-dependent RNR [113] (Fig. 4c) and therefore, they need partners such as the cobaviral hosts, able to synthesize vitamin B12. Many dinoflagellates are mixotrophic or heterotrophic, being able to ingest diverse prey, including bacteria [114], and their dependence on external sources of vitamin B12 has been documented previously [115-117].

Taking all this into consideration, we propose that at least some of the cobaviral hosts are frequently interacting with phagotrophic/mixotrophic protists, beyond just being grazed upon. It is possible that the cobaviral hosts, associated or not with phototrophic algae, have developed mechanisms to escape digestion in food vacuoles of predatory protists, in a similar way to amoebae-resistant bacteria [106, 107, 109, 118-120].

In their interactions with phototrophic and mixotrophic protists, marine Rhodobacteraceae form both mutualistic and pathogenic relationships, the latter resulting in protist lysis $[121,122]$. Therefore, by exerting control on their host populations, cobaviruses could have roles in biogeochemical cycling that go beyond the release of bacterial cellular components. They could indirectly affect both marine phytoplankton growth, and thus carbon fixation, and its lysis, and thus release of the fixed organic matter in the environment. Future studies are necessary to understand the roles that cobaviruses play in the environment and their impact on roseobacter populations.

\section{Conclusions}

This study significantly extends our knowledge of phages infecting organisms of the Roseobacter group, a key player in the cycling of organic matter in marine ecosystems. Using an approach that combines phage isolation with database mining for environmental phage genomes we have delineated the new Cobavirus group. Our biogeography survey included marine metagenomes from the viral, prokaryotic and protist fractions and is to date one of the largest surveys applied for a specific phage group. Cobaviruses impact Roseobacter populations at a global scale, from temperate to tropical marine waters, especially in coastal areas, and thus could have an influence on the biogeochemical cycling in these environments.

\footnotetext{
Acknowledgements We are grateful to Helge Giebel for collecting the water samples from the Heincke cruise, to Andrea Schlingloff for assistance in culture work and to Alba Filella Lopez de Lamadrid for assistance in enrichment optimization. We thank the captain and the crew of the RV Heincke for their support (grant AWI-HE440). We thank Simone Severitt and Nicole Heyer for excellent technical assistance regarding PacBio genome sequencing. We thank Matthew Sullivan for fruitful discussions and advice on the study. We are grateful to Bernhard Fuchs, Thomas Mock, Matthew Sullivan, Holly Simon, Frank Stewart, Christopher Francis, Brett Baker, Steven Hallam and Barbara Campbell for sharing the metadata from their
}

metagenomic projects with us. This work was supported by funds from Deutsche Forschungsgemeinschaft within the Collaborative Research Center TRR51 Roseobacter.

Author contributions CM designed the research, contributed to data analysis and drafted the manuscript. VB performed the laboratory phage work, contributed to data analysis and to manuscript drafting. $\mathrm{MN}$ and VB isolated ICBM2 phage. BB, CS and JO conducted PacBio sequencing, assembly, annotation and DTR recognition. AP and RD conducted Illumina sequencing and assembly. JMK and MG performed the VICTOR analysis. MD and TB calculated the $16 \mathrm{~S}$ rRNA trees. JP contributed to the host range tests. TB and MS advised through the course of research and contributed to data interpretation. All authors contributed to manuscript finalization.

\section{Compliance with ethical standards}

Conflict of interest The authors declare that they have no conflict of interest.

Publisher's note: Springer Nature remains neutral with regard to jurisdictional claims in published maps and institutional affiliations.

Open Access This article is licensed under a Creative Commons Attribution 4.0 International License, which permits use, sharing, adaptation, distribution and reproduction in any medium or format, as long as you give appropriate credit to the original author(s) and the source, provide a link to the Creative Commons license, and indicate if changes were made. The images or other third party material in this article are included in the article's Creative Commons license, unless indicated otherwise in a credit line to the material. If material is not included in the article's Creative Commons license and your intended use is not permitted by statutory regulation or exceeds the permitted use, you will need to obtain permission directly from the copyright holder. To view a copy of this license, visit http://creativecommons. org/licenses/by/4.0/.

\section{References}

1. Fuhrman JA. Marine viruses and their biogeochemical and ecological effects. Nature. 1999;399:541-8.

2. Suttle CA. Viruses in the sea. Nature. 2005;437:356-61.

3. Roux S, Brum JR, Dutilh BE, Sunagawa S, Duhaime MB, Loy A, et al. Ecogenomics and potential biogeochemical impacts of globally abundant ocean viruses. Nature. 2016;537:689-93.

4. Brum JR, Ignacio-Espinoza JC, Roux S, Doulcier G, Acinas SG, Alberti A, et al. Patterns and ecological drivers of ocean viral communities. Science. 2015;348:1261498.

5. Paez-Espino D, Eloe-Fadrosh EA, Pavlopoulos GA, Thomas AD, Huntemann M, Mikhailova N, et al. Uncovering Earth's virome. Nature. 2016;536:425-30.

6. Nishimura Y, Watai H, Honda T, Mihara T, Omae K, Roux S, et al. Environmental viral genomes shed new light on virus-host interactions in the ocean. mSphere. 2017;2:e00359-16.

7. Simon M, Scheuner C, Meier-Kolthoff JP, Brinkhoff T, WagnerDöbler I, Ulbrich M, et al. Phylogenomics of Rhodobacteraceae reveals evolutionary adaptation to marine and non-marine habitats. ISME J. 2017;11:1483-99.

8. Buchan A, González JM, Moran MA. Overview of the marine Roseobacter lineage. Appl Environ Microbiol. 2005;71:5665-77.

9. Newton RJ, Griffin LE, Bowles KM, Meile C, Gifford S, Givens $\mathrm{CE}$, et al. Genome characteristics of a generalist marine bacterial lineage. ISME J. 2010;4:784-98. 
10. Selje N, Simon M, Brinkhoff T. A newly discovered Roseobacter cluster in temperate and polar oceans. Nature. 2004;427:445-8.

11. Giebel H-A, Kalhoefer D, Lemke A, Thole S, Gahl-Janssen R, Simon M, et al. Distribution of Roseobacter RCA and SAR11 lineages in the North Sea and characteristics of an abundant RCA isolate. ISME J. 2011;5:8-19.

12. Lenk S, Moraru C, Hahnke S, Arnds J, Richter M, Kube M, et al. Roseobacter clade bacteria are abundant in coastal sediments and encode a novel combination of sulfur oxidation genes. ISME J. 2012;6:2178-87.

13. Zhang Y, Sun Y, Jiao N, Stepanauskas R, Luo H. Ecological genomics of the uncultivated marine Roseobacter lineage CHAB-I-5. Appl Environ Microbiol. 2016;82:2100-11.

14. Lamy D, Obernosterer I, Laghdass M, Artigas F, Breton E, Grattepanche JD, et al. Temporal changes of major bacterial groups and bacterial heterotrophic activity during a Phaeocystis globosa bloom in the eastern English Channel. Aquat Microb Ecol. 2009;58:95-107.

15. Buchan A, LeCleir GR, Gulvik CA, González JM. Master recyclers: features and functions of bacteria associated with phytoplankton blooms. Nat Rev Microbiol. 2014;12:686-98.

16. Teeling H, Fuchs BM, Bennke CM, Krüger K, Chafee M, Kappelmann L, et al. Recurring patterns in bacterioplankton dynamics during coastal spring algae blooms. eLife. 2016;5: e11888.

17. Wemheuer B, Wemheuer F, Hollensteiner J, Meyer F-D, Voget S, Daniel R. The green impact: bacterioplankton response toward a phytoplankton spring bloom in the southern North Sea assessed by comparative metagenomic and metatranscriptomic approaches. Front Microbiol. 2015;6:805.

18. Bakenhus I, Dlugosch L, Billerbeck S, Giebel H-A, Milke F, Simon M. Composition of total and cell-proliferating bacterioplankton community in early summer in the North Sea Roseobacters are the most active component. Front Microbiol. 2017;8:1771.

19. Wallace JC, Youngblood JE, Port JA, Cullen AC, Smith MN, Workman T, et al. Variability in metagenomic samples from the Puget sound: relationship to temporal and anthropogenic impacts. PLoS ONE. 2018;13:e0192412.

20. Li Z, Qu Z, Zhang X, Zhang X-H. Lentibacter algarum gen. nov., sp. nov., isolated from coastal water during a massive green algae bloom. Int J Syst Evol Microbiol. 2012;62(Pt 5):1042-7.

21. Hahnke S, Brock NL, Zell C, Simon M, Dickschat JS, Brinkhoff T. Physiological diversity of Roseobacter clade bacteria cooccurring during a phytoplankton bloom in the North Sea. Syst Appl Microbiol. 2013;36:39-48.

22. Pujalte MJ, Lucena T, Ruvira MA, Arahal DR, Macián MC. The family Rhodobacteraceae. In: Rosenberg E, DeLong EF, Lory S, Stackebrandt E, Thompson F (eds) The Prokaryotes. SpringerVerlag Berlin Heidelberg; 2014. p. 439-512.

23. Zhao Y, Wang K, Jiao N, Chen F. Genome sequences of two novel phages infecting marine roseobacters. Environ Microbiol. 2009;11:2055-64.

24. Ankrah NYD, Budinoff CR, Wilson WH, Wilhelm SW, Buchan A. Genome sequence of the Sulfitobacter sp. strain 2047-infecting lytic phage ФCB2047-B. Genome Announc. 2014;2:e00945-13.

25. Chan JZ-M, Millard AD, Mann NH, Schäfer H. Comparative genomics defines the core genome of the growing N4-like phage genus and identifies N4-like Roseophage specific genes. Front Microbiol. 2014;5:506.

26. Ji J, Zhang R, Jiao N. Complete genome sequence of Roseophage vB_DshP-R1, which infects Dinoroseobacter shibae DFL12. Stand Genom Sci. 2014;9:31.

27. Cai L, Yang Y, Jiao N, Zhang R. Complete genome sequence of vB_DshP-R2C, a N4-like lytic roseophage. Mar. Genomics. $2015 ; 22: 15-17$.
28. Li B, Zhang S, Long L, Huang S. Characterization and complete genome sequences of three N4-Like Roseobacter phages isolated from the South China Sea. Curr Microbiol. 2016;73:409-18.

29. Wittmann J, Klumpp J, Moreno Switt AI, Yagubi A, Ackermann $\mathrm{H}-\mathrm{W}$, Wiedmann $\mathrm{M}$, et al. Taxonomic reassessment of N4-like viruses using comparative genomics and proteomics suggests a new subfamily_Enquartavirinae. Arch Virol. 2015;160:3053-62.

30. Rohwer F, Segall A, Steward G, Seguritan V, Breitbart M, Wolven $\mathrm{F}$, et al. The complete genomic sequence of the marine phage Roseophage SIO1 shares homology with nonmarine phages. Limnol Oceanogr. 2000;45:408-18.

31. Chen F, Wang K, Stewart J, Belas R. Induction of multiple prophages from a marine bacterium: a genomic approach. Appl Environ Microbiol. 2006;72:4995-5001.

32. Zhang Y, Jiao N. Roseophage RDJL Phi1, infecting the aerobic anoxygenic phototrophic bacterium Roseobacter denitrificans OCh114. Appl Environ Microbiol. 2009;75:1745-9.

33. Kang I, Jang H, Oh H-M, Cho J-C. Complete genome sequence of Celeribacter bacteriophage P12053L. J Virol. 2012;86:8339-40.

34. Ankrah NYD, Budinoff CR, Wilson WH, Wilhelm SW, Buchan A. Genome sequences of two temperate phages, ФCB2047-A and ФСВ2047-C, infecting Sulfitobacter sp. Strain 2047. Genome Announc. 2014;2:e00945-13.

35. Liang Y, Zhang Y, Zhou C, Chen Z, Yang S, Yan C, et al. Complete genome sequence of the siphovirus Roseophage RDJL $\Phi 2$ infecting Roseobacter denitrificans OCh114. Mar. Genomics. 2016;25:17-19.

36. Zhan Y, Huang S, Voget S, Simon M, Chen F. A novel roseobacter phage possesses features of podoviruses, siphoviruses, prophages and gene transfer agents. Sci Rep. 2016;6:30372.

37. Tang K, Lin D, Zheng Q, Liu K, Yang Y, Han Y, et al. Genomic, proteomic and bioinformatic analysis of two temperate phages in Roseobacter clade bacteria isolated from the deep-sea water. BMC Genom. 2017;18:485.

38. Yang Y, Cai L, Ma R, Xu Y, Tong Y, Huang Y, et al. A novel Roseosiphophage isolated from the oligotrophic South China Sea. Viruses. 2017;9:109.

39. Angly F, Youle M, Nosrat B, Srinagesh S, Rodriguez-Brito B, McNairnie P, et al. Genomic analysis of multiple Roseophage SIO1 strains. Environ Microbiol. 2009;11:2863-73.

40. Hardies SC, Thomas JA, Black L, Weintraub ST, Hwang CY, Cho BC. Identification of structural and morphogenesis genes of Pseudoalteromonas phage $\varphi \mathrm{RIO}-1$ and placement within the evolutionary history of Podoviridae. Virology. 2016;489:116-27.

41. Hardies SC, Comeau AM, Serwer P, Suttle CA. The complete sequence of marine bacteriophage VpV262 infecting Vibrio parahaemolyticus indicates that an ancestral component of a T7 viral supergroup is widespread in the marine environment. Virology. 2003;310:359-71.

42. Paez-Espino D, Chen I-MA, Palaniappan K, Ratner A, Chu K, Szeto E, et al. IMG/VR: a database of cultured and uncultured DNA viruses and retroviruses. Nucleic Acids Res. 2017;45(D1): D457-D465.

43. Bolduc B, Youens-Clark K, Roux S, Hurwitz BL, Sullivan MB. iVirus: facilitating new insights in viral ecology with software and community data sets imbedded in a cyberinfrastructure. ISME J. 2017;11:7-14.

44. Merchant N, Lyons E, Goff S, Vaughn M, Ware D, Micklos D, et al. The iPlant collaborative: cyberinfrastructure for enabling data to discovery for the life sciences. PLoS Biol. 2016;14:e1002342.

45. Price MN, Dehal PS, Arkin AP. FastTree 2--approximately maximum-likelihood trees for large alignments. PLoS One. 2010;5:e9490.

46. Noguchi H, Taniguchi T, Itoh T. MetaGeneAnnotator: detecting species-specific patterns of ribosomal binding site for precise 
gene prediction in anonymous prokaryotic and phage genomes. DNA Res. 2008;15:387-96.

47. Roux S, Enault F, Hurwitz BL, Sullivan MB. VirSorter: mining viral signal from microbial genomic data. PeerJ. 2015;3:e985.

48. Meier-Kolthoff JP, Göker M. VICTOR: genome-based phylogeny and classification of prokaryotic viruses. Bioinformatics. 2017;33:3396-404.

49. Meier-Kolthoff JP, Auch AF, Klenk H-P, Göker M. Genome sequence-based species delimitation with confidence intervals and improved distance functions. BMC Bioinforma. 2013;14:60.

50. Lefort V, Desper R, Gascuel O. FastME 2.0: a comprehensive, accurate, and fast distance-based phylogeny inference program. Mol Biol Evol. 2015;32:2798-2800.

51. Farris JS. Estimating phylogenetic trees from distance matrices. Am Nat. 1972;106:645-68.

52. Letunic I, Bork P. Interactive tree of life (iTOL) v3: an online tool for the display and annotation of phylogenetic and other trees. Nucleic Acids Res. 2016;44(W1):W242-5.

53. Göker M, García-Blázquez G, Voglmayr H, Tellería MT, Martín MP. Molecular taxonomy of phytopathogenic fungi: a case study in Peronospora. PLoS One. 2009;4:e6319.

54. Meier-Kolthoff JP, Hahnke RL, Petersen J, Scheuner C, Michael V, Fiebig A, et al. Complete genome sequence of DSM 30083 (T), the type strain (U5/41(T)) of Escherichia coli, and a proposal for delineating subspecies in microbial taxonomy. Stand Genom Sci. 2014;9:2.

55. Finn RD, Attwood TK, Babbitt PC, Bateman A, Bork P, Bridge AJ, et al. InterPro in 2017-beyond protein family and domain annotations. Nucleic Acids Res. 2017;45(D1):D190-9.

56. Jones P, Binns D, Chang H-Y, Fraser M, Li W, McAnulla C, et al. InterProScan 5: genome-scale protein function classification. Bioinformatics. 2014;30:1236-40.

57. Grazziotin AL, Koonin EV, Kristensen DM. Prokaryotic virus orthologous groups (pVOGs): a resource for comparative genomics and protein family annotation. Nucleic Acids Res. 2017;45: D491-D498.

58. Eddy SR. Accelerated profile HMM searches. PLoS Comput Biol. 2011;7:e1002195.

59. Lowe TM, Chan PP. tRNAscan-SE on-line: integrating search and context for analysis of transfer RNA genes. Nucleic Acids Res. 2016;44(W1):W54-7.

60. Guy L, Roat Kultima J, Andersson SGE. genoPlotR: comparative gene and genome visualization in R. Bioinformatics. 2010;26:2334-5.

61. Kearse M, Moir R, Wilson A, Stones-Havas S, Cheung M, Sturrock S, et al. Geneious basic: an integrated and extendable desktop software platform for the organization and analysis of sequence data. Bioinformatics. 2012;28:1647-9.

62. A Rambaut. FigTree 1.4.3-a graphical viewer of phylogenetic trees and a program for producing publication-ready figures. 2006. http://tree.bio.ed.ac.uk/software/figtree/.

63. Ludwig W, Strunk O, Westram R, Richter L, Meier H, Buchner A, et al. ARB: a software environment for sequence data. Nucleic Acids Res. 2004;32:1363-71.

64. Alberti A, Poulain J, Engelen S, Labadie K, Romac S, Ferrera I, et al. Viral to metazoan marine plankton nucleotide sequences from the Tara Oceans expedition. Sci Data. 2017;4:170093.

65. Roux S, Emerson JB, Eloe-Fadrosh EA, Sullivan MB. Benchmarking viromics: an in silico evaluation of metagenomeenabled estimates of viral community composition and diversity. PeerJ. 2017;5:e3817.

66. Villamor J, Ramos-Barbero MD, González-Torres P, Gabaldón T, Rosselló-Móra R, Meseguer I, et al. Characterization of ecologically diverse viruses infecting co-occurring strains of cosmopolitan hyperhalophilic Bacteroidetes. ISME J. 2018;12:424-37.
67. Sakowski EG, Munsell EV, Hyatt M, Kress W, Williamson SJ, Nasko DJ, et al. Ribonucleotide reductases reveal novel viral diversity and predict biological and ecological features of unknown marine viruses. Proc Natl Acad Sci USA. 2014; 111:15786-91.

68. Hardies SC, Hwang YJ, Hwang CY, Jang GI, Cho BC. Morphology, physiological characteristics, and complete sequence of marine bacteriophage $\phi \mathrm{RIO}-1$ infecting Pseudoalteromonas marina. J Virol. 2013;87:9189-98.

69. Illumina I Nextera XT library prep: tips and troubleshooting. 2015. https://support.illumina.com/content/dam/illuminasupport/documents/documentation/chemistry_documentation/sa mplepreps_nextera/nextera-xt/nextera-xt-troubleshooting-guide. pdf.

70. Merrill BD, Ward AT, Grose JH, Hope S. Software-based analysis of bacteriophage genomes, physical ends, and packaging strategies. BMC Genom. 2016;17:679.

71. Escarmis C, Garcia P, Mendez E, López R, Salas M, García E. Inverted terminal repeats and terminal proteins of the genomes of pneumococcal phages. Gene. 1985;36:341-8.

72. Savilahti H, Bamford DH, Protein-primed DNA. replication: role of inverted terminal repeats in the Escherichia coli bacteriophage PRD1 life cycle. J Virol. 1993;67:4696-703.

73. Kulczyk AW, Richardson CC. The replication system of bacteriophage T7. Enzymes. 2016;39:89-136.

74. Serwer P. T3/T7 DNA packaging. In: Catalano CE, editor. Viral genome packaging machines: genetics, structure, and mechanism. Georgetown, New York: Landes Bioscience/Eurekah.com; 2005. p. 59-79.

75. Dwivedi B, Xue B, Lundin D, Edwards RA, Breitbart M. A bioinformatic analysis of ribonucleotide reductase genes in phage genomes and metagenomes. BMC Evol Biol. 2013;13:33.

76. Sengupta R, Holmgren A. Thioredoxin and glutaredoxinmediated redox regulation of ribonucleotide reductase. World $\mathrm{J}$ Biol Chem. 2014;5:68-74.

77. Leduc D, Graziani S, Meslet-Cladiere L, Sodolescu A, Liebl U, Myllykallio H. Two distinct pathways for thymidylate (dTMP) synthesis in (hyper)thermophilic bacteria and Archaea. Biochm Soc Trans. 2004;32:231-5.

78. Gross M, Marianovsky I, Glaser G. MazG-a regulator of programmed cell death in Escherichia coli. Mol Microbiol. 2006;59:590-601.

79. Clokie MRJ, Mann NH. Marine cyanophages and light. Environ Microbiol. 2006;8:2074-82.

80. Smet JD, Zimmermann M, Kogadeeva M, Ceyssens P-J, Vermaelen W, Blasdel B, et al. High coverage metabolomics analysis reveals phage-specific alterations to Pseudomonas aeruginosa physiology during infection. ISME J. 2016;10:1823.

81. Summer EJ, Berry J, Tran TAT, Niu L, Struck DK, Young R. Rz/Rz1 lysis gene equivalents in phages of Gram-negative hosts. J Mol Biol. 2007;373:1098-112.

82. Hurwitz BL, Hallam SJ, Sullivan MB. Metabolic reprogramming by viruses in the sunlit and dark ocean. Genome Biol. 2013;14: R123.

83. Kemp P, Garcia LR, Molineux IJ. Changes in bacteriophage T7 virion structure at the initiation of infection. Virology. 2005; 340:307-17.

84. Seed KD, Bodi KL, Kropinski AM, Ackermann H-W, Calderwood SB, Qadri F, et al. Evidence of a dominant lineage of Vibrio cholerae-specific lytic bacteriophages shed by cholera patients over a 10-year period in Dhaka, Bangladesh. mBio. 2011;2:e00334-10.

85. Liu Y, Du J, Lai Q, Dong C, Shao Z. Nioella sediminis sp. nov., isolated from surface sediment and emended description of the genus Nioella. Int J Syst Evol Microbiol. 2017;67:1271-4. 
86. Young R. Phage lysis: do we have the hole story yet? Curr Opin Microbiol. 2013;16:790-7.

87. Young R. Phage lysis: Three steps, three choices, one outcome. J Microbiol. 2014;52:243-58.

88. Hu B, Margolin W, Molineux IJ, Liu J. The bacteriophage T7 virion undergoes extensive structural remodeling during infection. Science. 2013;339:576-9.

89. Guo F, Liu Z, Fang P-A, Zhang Q, Wright ET, Wu W, et al. Capsid expansion mechanism of bacteriophage $\mathrm{T} 7$ revealed by multistate atomic models derived from cryo-EM reconstructions. Proc Natl Acad Sci USA. 2014;111:E4606-14.

90. Cuervo A, Chagoyen M, Pulido-Cid M, Camacho A, Carrascosa JL. Structural characterization of T7 tail machinery reveals a conserved tubular structure among other Podoviridae family members and suggests a common mechanism for DNA delivery. Bacteriophage. 2013;3:e27011.

91. Leiman PG, Arisaka F, van Raaij MJ, Kostyuchenko VA, Aksyuk AA, Kanamaru S, et al. Morphogenesis of the T4 tail and tail fibers. Virol J. 2010;7:355.

92. Golomidova AK, Kulikov EE, Prokhorov NS, Guerrero-Ferreira RC, Knirel YA, Kostryukova ES, et al. Branched lateral tail fiber organization in T5-like bacteriophages DT57C and DT571/2 is revealed by genetic and functional analysis. Viruses. 2016;8:26.

93. Sañudo-Wilhelmy SA, Gómez-Consarnau L, Suffridge C, Webb EA. The role of B vitamins in marine biogeochemistry. Ann Rev Mar Sci. 2014;6:339-67.

94. Arndt D, Grant JR, Marcu A, Sajed T, Pon A, Liang Y, et al. PHASTER: a better, faster version of the PHAST phage search tool. Nucleic Acids Res. 2016;44(W1):21.

95. Breitbart M, Salamon P, Andresen B, Mahaffy JM, Segall AM, Mead D, et al. Genomic analysis of uncultured marine viral communities. Proc Natl Acad Sci USA. 2002;99:14250-5.

96. Bench SR, Hanson TE, Williamson KE, Ghosh D, Radosovich M, Wang K, et al. Metagenomic characterization of Chesapeake Bay virioplankton. Appl Environ Microbiol. 2007;73:7629-41.

97. Hwang J, Park SY, Park M, Lee S, Jo Y, Cho WK, et al. Metagenomic characterization of viral communities in Goseong Bay. Korea Ocean Sci J. 2016;51:599-612.

98. Hwang J, Park SY, Park M, Lee S, Lee T-K. Seasonal dynamics and metagenomic characterization of marine viruses in Goseong Bay, Korea. PLoS One. 2017;12:e0169841.

99. Duarte CM. Seafaring in the 21st century: the Malaspina 2010 circumnavigation expedition. Limnol Oceanogr Bull. 2015;24:11-14.

100. Kim Y, Aw TG, Rose JB. Transporting ocean viromes: Invasion of the aquatic biosphere. PLoS One. 2016;11:e0152671.

101. Vargas CD, Audic S, Henry N, Decelle J, Mahé F, Logares R, et al. Eukaryotic plankton diversity in the sunlit ocean. Science. 2015;348:1261605.

102. Fiebig A, Pradella S, Petersen J, Päuker O, Michael V, Lünsdorf $\mathrm{H}$, et al. Genome of the R-body producing marine alphaproteobacterium Labrenzia alexandrii type strain (DFL-11(T)). Stand Genom Sci. 2013;7:413-26.

103. Chen Z, Zhang J, Lei X, Zhang B, Cai G, Zhang H, et al. Influence of plaque-forming bacterium, Rhodobacteraceae $\mathrm{sp}$. on the growth of Chlorella vulgaris. Bioresour Technol. 2014;169:784-8.

104. Guannel ML, Horner-Devine MC, Rocap G. Bacterial community composition differs with species and toxigenicity of the diatom Pseudo-nitzschia. Aquat Microb Ecol. 2011;64:117-33.

105. Green DH, Hart MC, Blackburn SI, Bolch CJS. Bacterial diversity of Gymnodinium catenatum and its relationship to dinoflagellate toxicity. Aquat Microb Ecol. 2010;61:73-87.
106. Pagnier I, Raoult D, La Scola B. Isolation and identification of amoeba-resisting bacteria from water in human environment by using an Acanthamoeba polyphaga co-culture procedure. Environ Microbiol. 2008;10:1135-44.

107. Pagnier I, Valles C, Raoult D, La Scola B. Isolation of Vermamoeba vermiformis and associated bacteria in hospital water. Microb Pathog. 2015;80:14-20.

108. Delafont V, Brouke A, Bouchon D, Moulin L, Héchard Y. Microbiome of free-living amoebae isolated from drinking water. Water Res. 2013;47:6958-65.

109. Paquet VE, Charette SJ. Amoeba-resisting bacteria found in multilamellar bodies secreted by Dictyostelium discoideum: social amoebae can also package bacteria. FEMS Microbiol Ecol. 2016;92:fiw025.

110. Taylor-Brown A, Vaughan L, Greub G, Timms P, Polkinghorne A. Twenty years of research into Chlamydia-like organisms: a revolution in our understanding of the biology and pathogenicity of members of the phylum Chlamydiae. Pathog Dis. 2015;73:1-15.

111. Hoshina R, Shimizu M, Makino Y, Haruyama Y, Ueda S-I, Kato $\mathrm{Y}$, et al. Isolation and characterization of a virus $(\mathrm{CvV}-\mathrm{BW} 1)$ that infects symbiotic algae of Paramecium bursaria in Lake Biwa, Japan. Virol J. 2010;7:222.

112. Quispe CF, Esmael A, Sonderman O, McQuinn M, Agarkova I, Battah M, et al. Characterization of a new chlorovirus type with permissive and non-permissive features on phylogenetically related algal strains. Virology. 2017;500:103-13.

113. Crona M, Avesson L, Sahlin M, Lundin D, Hinas A, Klose R, et al. A rare combination of ribonucleotide reductases in the social amoeba Dictyostelium discoideum. J Biol Chem. 2013;288:8198-208.

114. Jeong HJ, Du Yoo Y, Kim JS, Seong KA, Kang NS, Kim TH. Growth, feeding and ecological roles of the mixotrophic and heterotrophic dinoflagellates in marine planktonic food webs. Ocean Sci J. 2010;45:65-91.

115. Tang YZ, Koch F, Gobler CJ. Most harmful algal bloom species are vitamin B1 and B12 auxotrophs. Proc Natl Acad Sci USA. 2010;107:20756-61.

116. Cruz-López R, Maske H. The vitamin B1 and B12 required by the marine dinoflagellate Lingulodinium polyedrum can be provided by its associated bacterial community in culture. Front Microbiol. 2016;7:560.

117. Wagner-Döbler I, Ballhausen B, Berger M, Brinkhoff T, Buchholz I, Bunk B, et al. The complete genome sequence of the algal symbiont Dinoroseobacter shibae: a hitchhiker's guide to life in the sea. ISME J. 2010;4:61-77.

118. Schmitz-Esser S, Toenshoff ER, Haider S, Heinz E, Hoenninger VM, Wagner M, et al. Diversity of bacterial endosymbionts of environmental acanthamoeba isolates. Appl Environ Microbiol. 2008;74:5822-31.

119. Bertelli C, Greub G. Lateral gene exchanges shape the genomes of amoeba-resisting microorganisms. Front Cell Infect Microbiol. 2012;2:110

120. Schulz F, Tyml T, Pizzetti I, Dyková I, Fazi S, Kostka M, et al. Marine amoebae with cytoplasmic and perinuclear symbionts deeply branching in the Gammaproteobacteria. Sci Rep. 2015;5:13381.

121. Wang H, Tomasch J, Jarek M, Wagner-Döbler I. A dual-species co-cultivation system to study the interactions between Roseobacters and dinoflagellates. Front Microbiol. 2014;5:311.

122. Segev E, Wyche TP, Kim KH, Petersen J, Ellebrandt C, Vlamakis $\mathrm{H}$, et al. Dynamic metabolic exchange governs a marine algal-bacterial interaction. Elife 2016;5:e17473. 